ORIGINAL ARTICLE

\title{
X-Ray-Free Ultrasound-Guided Percutaneous Nephrolithotomy at Zagazig University Hospital
}

\author{
Salem Ahmed Salem Khalil ${ }^{I}$, Mohammed Ahmed Kamel Omran ${ }^{I}$, Ahmed Mohammed Eliwa ${ }^{I}$, \\ Akram Abdul-Rahman Bin Ashour ${ }^{I^{*}}$. \\ I Department of Urology, Faculty of Medicine, Zagazig University, Sharkia, Egypt
}

*Corresponding author:

Akram Abdul Rahman Bin Ashour

Department of Urology, Faculty of Medicine, Zagazig University, Sharkia, Egypt

akrum85@yahoo.com

Submit Date:05-08-2019

Revise Date:01-09-2019

Accept Date:03-09-2019
ABSTRACT
Background: Nephrolithiasis is a significant worldwide source of morbidity. This study aims to evaluate the efficacy and safety of US guided PCNL for isolated renal pelvis stone $>20 \mathrm{~mm}$ in maximum diameter. Methods: A prospective interventional study was conducted on a group of 24 patients with renal stones treated by US guided PCNL at Zagazig University Hospital, Department of Urology. All cases that fit the inclusion criteria were enrolled in our study with informed consent. Results: shows that the age of the study group was $(35.8 \pm 8.5)$ ranged from (23 to 51) years, their BMI was $(23.5 \pm 3.8)$ ranged from (18 to 30$) \mathrm{kg} / \mathrm{m} 2$ and $(79.2 \%)$ of them were males. Also shows that $(70.8 \%)$ of the study group didn't have any chronic diseases, $(12.5 \%)$ of them were hypertensive and (12.5\%) were hypertensive\& diabetic. Also shows that the stone size of the study group ranged from (22 to 35$) \mathrm{mm}$, stone density ranged from (385 to 1570$) \mathrm{HU}$, $(58.3 \%)$ had left renal pelvis stone and $(87.5 \%)$ of them were radio-opaque. Success rate of procedure under U.S guidance was (87.5\%) (success cases) of the remaining $(12.5 \%)$ we failed to get an access under US guidance so we needed to conversion to conventional fluoroscopic guidance (failed cases) after 3 trials under US guidance. Conclusion: Percutaneous nephrolithotomy with ultrasound guidance is a good alternative to the fluoroscopic method, can be performed safely without radiation exposure to the patients and medical staff, with satisfactory outcomes without any major complications, in patients with single renal pelvis stone with mild to moderate hydronephrosis.

Key words: Percutaneous nephrolithotomy; Ultrasound; Extracorporeal Shock Wave Lithotripsy

\section{INTRODUCTION}

$\mathbf{N}$ ephrolithiasis is a significant worldwide source of morbidity, constituting a common urologic disease that affects between $10 \%$ and $15 \%$ of the world population, recent technologic and surgical advances have replaced the need for open surgery with less invasive procedures, such as percutaneous nephrolithotomy (PCNL) and extracorporeal shock wave lithotripsy [1] .

Percutaneous nephrolithotomy is a procedure commonly performed by urologists worldwide. it has become the mainstay surgical treatment for renal stones larger than $20 \mathrm{~mm}$ and those refractory to ESWL[2] .

Nevertheless, one concern related to this procedure is the possible long term effects of ionizing radiation exposure sustained by the surgeon, medical personnel, and patient during the operation which is usually guided by fluoroscopic imaging [3] .

The importance of reducing radiation exposure should not be underestimated, both for the physician as well as the patient. This is particularly relevant in younger patients as radiation exposure is correlated with increased risk for malignancy over time [4]. 
The utilization of ultrasound (US) can obviate the need for ionizing radiation exposure intraoperatively and provide a reliable method for the localization of renal stones. It can help surgeons create an appropriate access into the collecting system via a posterior calyx, guide tract dilation, and even confirm stone clearance after the procedure is completed . In addition, it can be an ideal imaging modality for special patient populations, including pediatric patients $[\mathbf{5 , 6}]$

\section{METHODS}

A prospective interventional study was conducted on a group of 24 patients with renal stones treated by US guided pcnl at Zagazig University Hospital, Department of Urology. All cases that fit the inclusion criteria were enrolled in our study with informed consent.

Written informed consent was obtained from all participants and the study was approved by the research ethical committee of Faculty of Medicine, Zagazig University. The work has been carried out in accordance with The Code of Ethics of the World Medical Association (Declaration of Helsinki) for studies involving humans.

Patient group: A number of 24 cases that fit the inclusion criteria were admitted to our hospital, in the period from november 2018 to march 2019 enrolled in the study.

Inclusion criteria: patients scheduled for percutaneous nephrolithotomy due to isolate renal pelvis stone $>20 \mathrm{~mm}$ in maximum diameter.

Exclusion criteria: 1- Bleeding tendency. 2Renal or uretral anomalies. 3- patients with multiple stones.

(1) Preoperative :

History taking : Including personal history age, sex, occupation, complaint, past history of prior operations or chronic diseases. Patients were asked about prior pelvic surgery or radiation. Previous urological operations. History of present illness.

Routine physical examination.

Routine pre-operative laboratory investigations including: Complete blood count (CBC).

Blood sugar tests. Renal function test (serum creatinine \&blood urea). liver function test (ALT, AST, ALP, albumin and bilirubin) .
Urinalysis + urine culture. PT, APTT, INR. Hepatits and HIV.

Radiological investigation: To determine number, site, size, density and laterality of renal stones Pelviabdominal ultrasound.

o Plain KUB (Kidney-ureters-bladder).

o None contrast abdomen and pelvis spiral CT.

Before participation in the study an informed consent was taken from all patients, and patients were informed about the procedure (advantages and disadvantages) possible complications and or failure

\section{(2) Intraoperative:}

First, we mark the ipsilateral posterior axillary line while the patient is standing before anesthesia and preoperative prophylactic intravenous antibiotics were administered after induction of anesthesia.

After induction of anesthesia (general or spinal regional anesthesia) and before PCNL, an open-ended 6-French ureteral catheter was inserted into the ipsilateral ureter via cystoscope, saline was injected through the ureteral catheter and observation of saline turbidity (water jet) in the pelvis by US to confirm that the tip of the ureteral catheter in the renal pelvis.

Then patients were changed to Flank free modified supine position_and safely secured to the operative table (figure 1).

Percutaneous renal access was obtained by the operating surgeon using ultrasound guidance without a needle guide . we used a 3.5- $\mathrm{MHz}$ convex abdominal transducer to exclude the presence of any organ in the path of the puncture and to localize the stone position as well as an ideally suited posterior calyx for puncture.

The skin was punctured posteriorly to the posterior axillary line, an 18- gauge needle was introduced into the most convex point of the targeted calyx under real-time ultrasound monitoring (figure 2).

In the absence of hydronephrosis, saline was injected retrograde through the ureteral catheter to dilate the collecting system for easier imaging.

Entry into the collecting system was confirmed with either efflux of urine or aspiration through the puncture needle (figure 3). 
After removal of the stylet, a J-tipped guide wire was inserted into the renal pelvis or down the proximal ureter, using ultrasound imaging to visualize the wire passing into the collecting system (figure 4).

After a $1.0-\mathrm{cm}$ skin incision was made, we performed single-shot dilation with a 28 Fr Amplatz dilator, then a 30 Fr Amplatz sheath was passed in, and then 28 Fr rigid nephroscope inserted.

All steps of dilatation were monitored ultrasonographically, the instrument's shadow while entering the system was visible by US (figure 5).

Pelvicaliceal system orientation and stone identification then stones disintegration were performed in the conventional manner, using a pneumatic lithotripter and or laser (figure 6).

Stone clearance was confirmed at the end of procedure with ultrasound imaging and with nephroscope.

The appropriate double-J stent was routinely maintained in place following PCNL under direct vision from below by ureteroscope and above by nephroscope, and this stent was maintained in place for 2-4 weeks post operatively.

Finally, a 26 Fr nephrostomy tube was inserted, fixed and closed then the incision was sutured with $3 / 0$ nylon suture.

\section{Intraoperative evaluation of the procedure} regarding:

-Success of procedure under US guide.

-Conversion rate to conventional fluoroscopy screening (after 3 trials of puncture under US guidance).

-Total operative time (defined as time calculated from initial cystoscopy for ureteral catheter placement until the placement of JJ stent).

-Intraoperative complications.

-Need for blood transfusion.

\section{(3) postoperative:}

On the first post-operative day :

(1) A blood count test was performed to assess the change in the patient's hemoglobin level.
(2) The Foley catheters were removed if haematuria was not evident.

(3) Plain abdominal radiography (KUB) and ultrasonography were performed.

(4) Nephrostomy tubes were removed in 1st post-operative day.

Patients were followed at our outpatient clinic using plain abdominal radiography or non-contrast abdomen \& pelvis spiral CT until they were stone free.

The demographic variables and the intra and postoperative surgical and follow up outcomes were recorded and evaluated.

\section{Postoperative evaluation of the procedure regarding: \\ Primary end point:}

-Success of puncture, tract creation and confirmation of stone clearance under US guidance.

\section{Secondary end points:}

-Postoperative complication.

-Stone free rate (complete stone free or presence of residual fragments less than $4 \mathrm{~mm}$ in largest dimension).

-Need for auxiliary procedure.

-Hospital stay.

\section{Statistical analysis}

Data collected throughout history, basic clinical examination, laboratory investigations and outcome measures coded, entered and analyzed using Microsoft Excel software. Data were then imported into Statistical Package for the Social Sciences (SPSS version 20.0) (Statistical Package for the Social Sciences) software for analysis. According to the type of data qualitative represent as number and percentage, quantitative continues group represent by mean $\pm \mathrm{SD}$, the following tests were used to test differences for significance;. difference and association of qualitative variable by Chi square test (X2) . Differences between quantitative independent groups by $\mathrm{t}$ test. $\mathrm{P}$ value was set at $<0.05$ for significant results $\&<0.001$ for high significant result. 


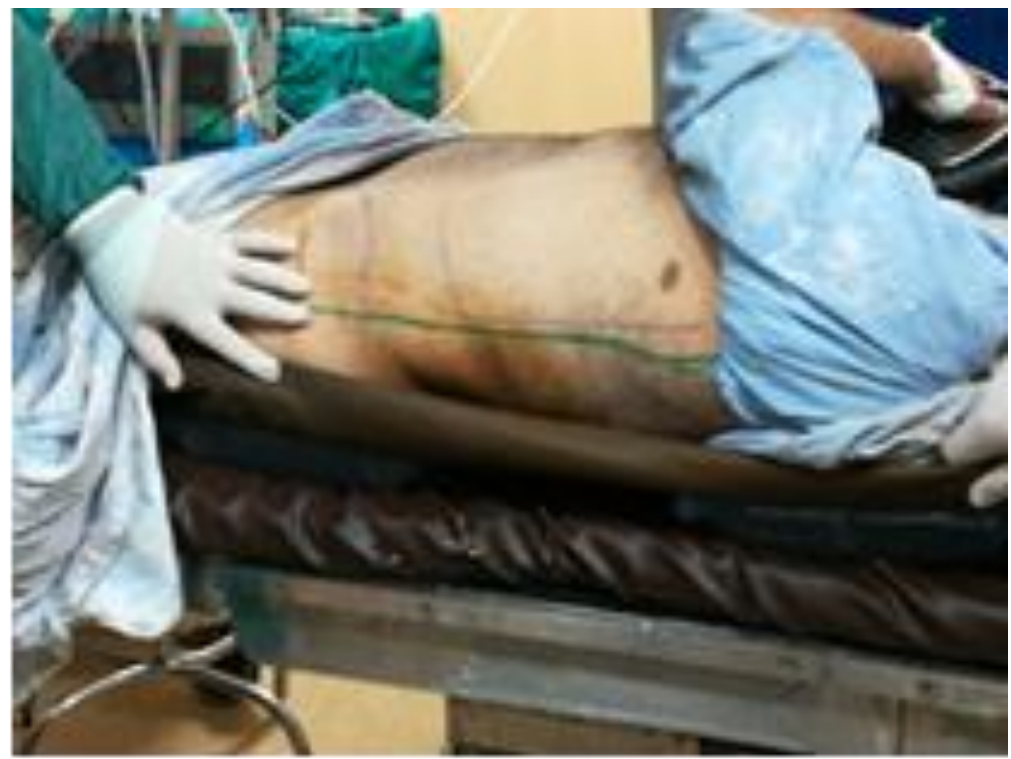

Figure 1. Our patient position, in flank free modified supine position.

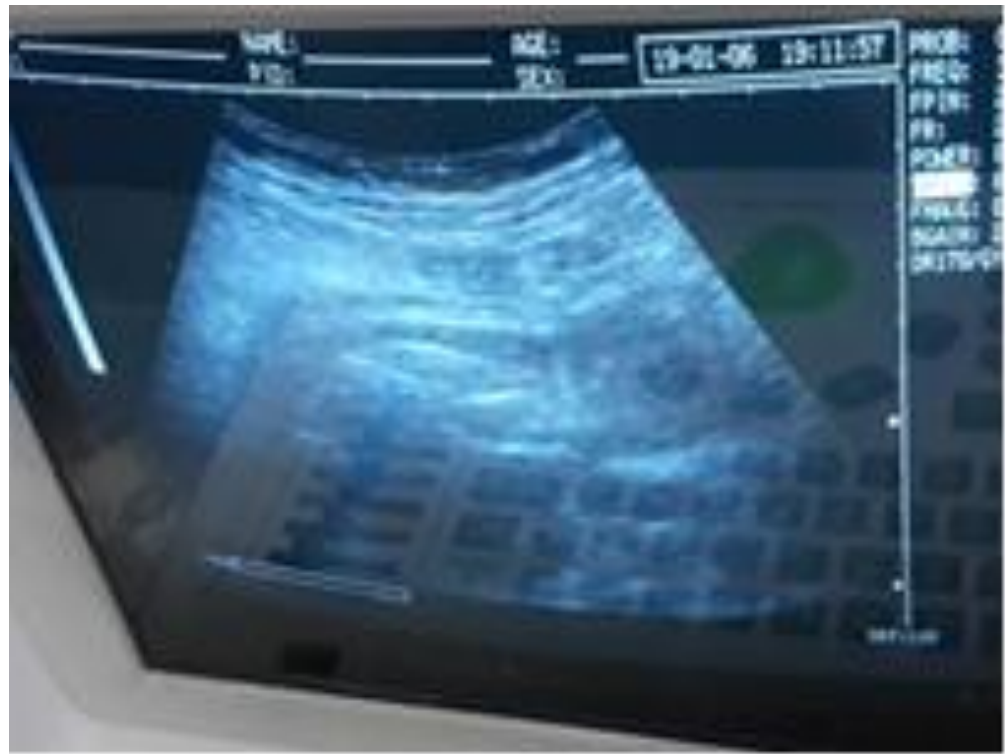

Figure 2. The shadow of needle when it enters PCS. 


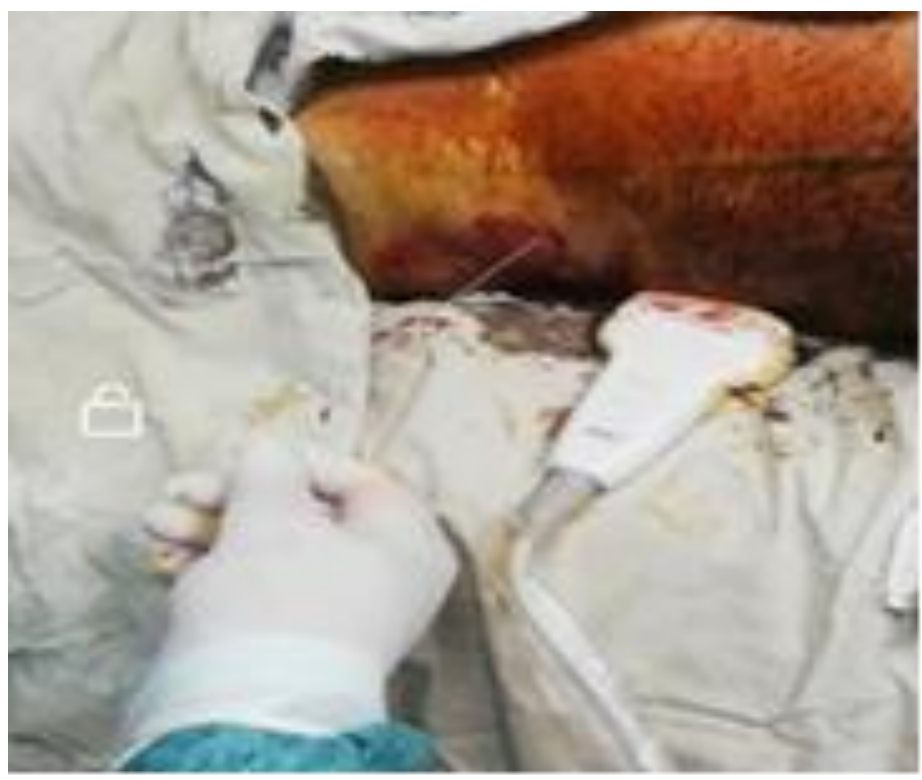

Figure 3. Efflux of urine after puncture of PCS

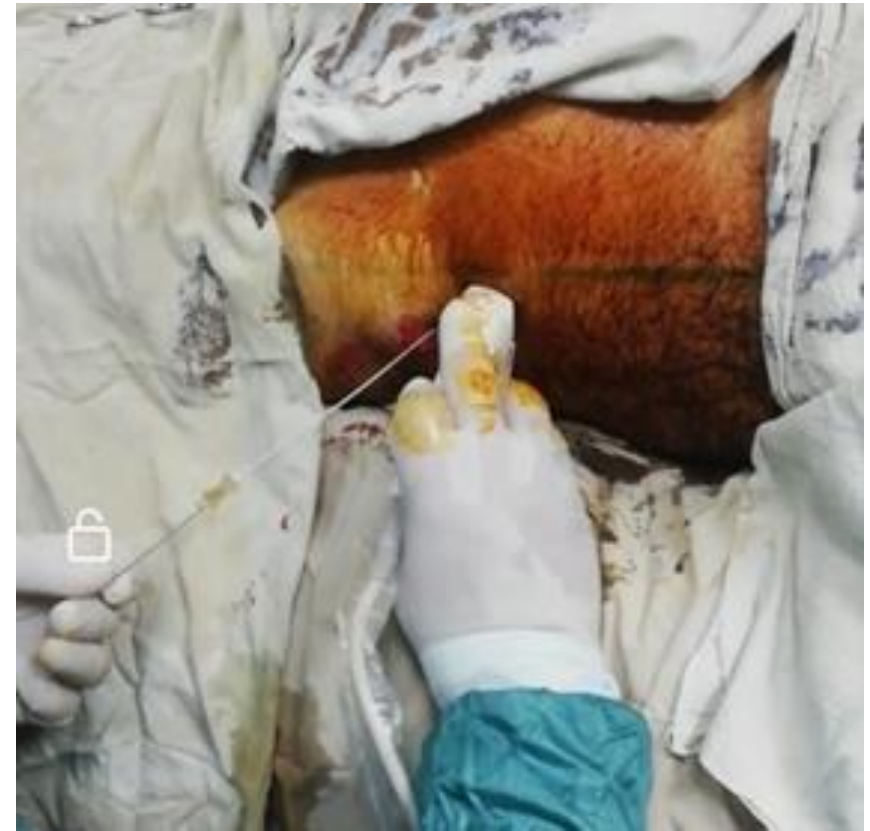

Figure 4. Insertion of guide wire after puncture of PCS 


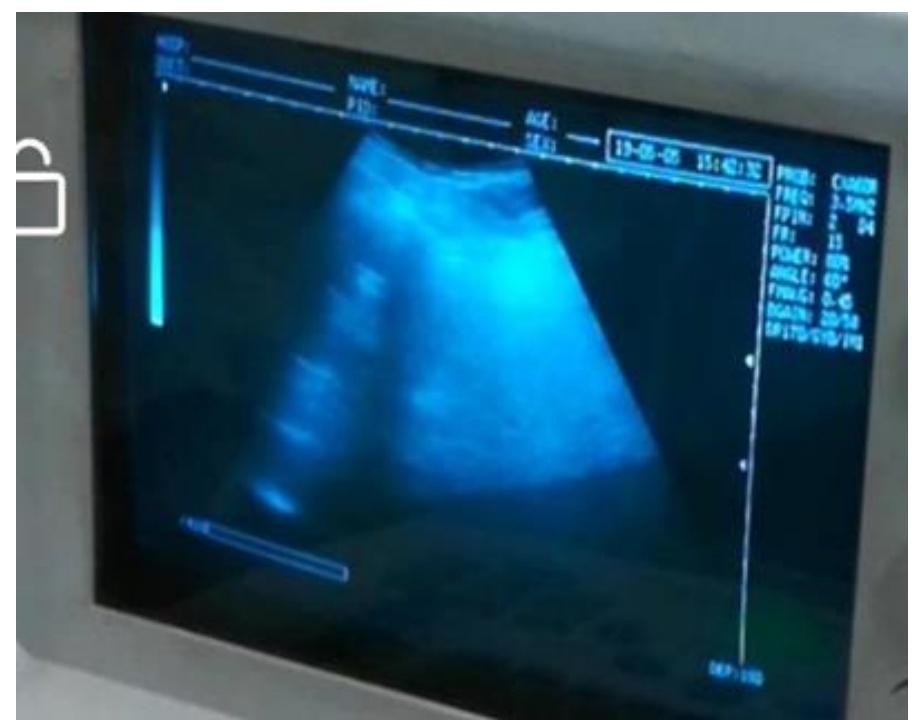

Figure 5. The instrument's shadow while entering the system was visible by US.

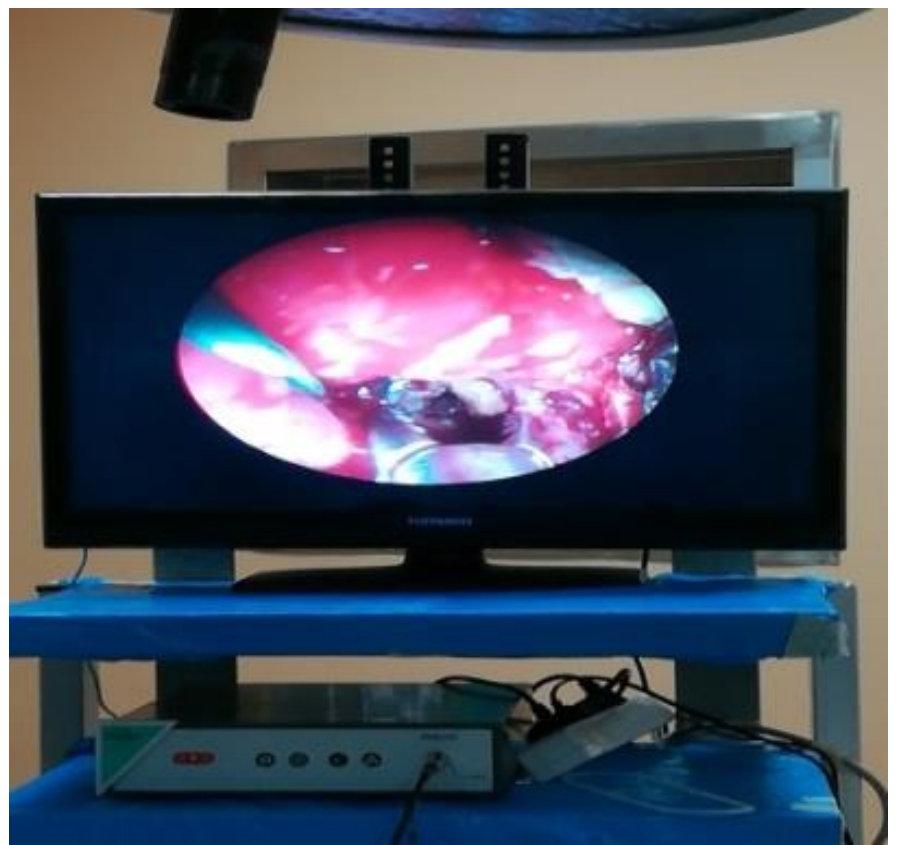

Figure 6. Stone disintegration and extraction using pneumatic lithotripter device or Ho:YAG laser and grasper

\section{RESULTS}

Our results showed that :

Table 1, This table shows that the age of the study group was $(35.8 \pm 8.5)$ ranged from (23 to 51$)$ years, their BMI was $(23.5 \pm 3.8)$ ranged from (18 to 30$) \mathrm{kg} / \mathrm{m} 2$ and $(79.2 \%)$ of them were males. Also shows that $(70.8 \%)$ of the study group didn't have any chronic diseases, $(12.5 \%)$ of them were hypertensive and $(12.5 \%)$ were hypertensive\& diabetic. Also shows that the stone size of the study group ranged from (22 to 35$) \mathrm{mm}$, stone density ranged from (385 to 1570) HU, (58.3\%) had left renal pelvis stone and $(87.5 \%)$ of them were radio-opaque.

Table 2, This table shows the $\mathrm{Hb}$ level of the study group before operation was $(13.19 \pm 0.89)$ and after operation was $(12.71 \pm 0.85)$ also average $\mathrm{Hb}$ drop was $(0.47 \pm 0.26)$, and $(29.2 \%)$ of the study group had grade $1 \& 2$ hydronephrosis.

Table 3, This table shows that $(87.5 \%)$ of the study group were stone free, and $(12.5 \%)$ had significant stone residual, shifted to auxiliary maneuver (ESWL ) and become stone free after one session of ESWL was performed after 2 wks, and in our study no needed for 
2nd look PCNL, and regarding the duration of hospital stay in the study group was $(2.29 \pm 0.24)$ days ranged from $(2-4)$ days. Also this table shows that no one of the study group had any intraoperative complications (100.0\%).

Table 4, This table shows that most of the study group (54.2\%) had no post-operative complications, $\{4$ patients had transient hematuria (grade I Clavien System) managed using good hydration, 2 patients had only fever (grade I Clavien System) managed with antipyretic $\} \&\{3$ patients had UTI and fever (grade II Clavien System) managed using antipyretic and antibiotics according to urine culture\& sensitivity, also 2 patients had hematuria (grade II Clavien System) managed using good hydration, anti-hemorrhage drugs \}

Table 5, This table showing that 3 patients shifted to auxiliary maneuver (ESWL ) and become stone free after one session of ESWL was performed after $2 \mathrm{wks}$, one of them was among our successful cases and the others were among failed cases, also showing success rate of procedure under US guidance was $(87.5 \%)$.

Table 1. Patients and stone characteristics.

\begin{tabular}{|c|c|c|}
\hline Variable & \multicolumn{2}{|c|}{$\begin{array}{l}\text { The study group }(24) \\
\text { Mean } \pm \text { SD } \\
\text { (Range) }\end{array}$} \\
\hline $\begin{array}{c}\text { Age } \\
\text { (years): }\end{array}$ & \multicolumn{2}{|c|}{$\begin{array}{c}35.8 \pm 8.4 \\
(23-51)\end{array}$} \\
\hline $\begin{array}{c}B M I \\
(\mathrm{~kg} / \mathrm{m} 2)\end{array}$ & \multicolumn{2}{|c|}{$\begin{array}{c}23.5 \pm 3.8 \\
(18-30)\end{array}$} \\
\hline Sex distribution & $\mathrm{NO}(24)$ & $\%$ \\
\hline Male & 19 & $79.2 \%$ \\
\hline Female & 5 & $20.8 \%$ \\
\hline Comorbidities & $\mathrm{NO}(24)$ & $\%$ \\
\hline No & 17 & $70.8 \%$ \\
\hline Hypertensive & 3 & $12.5 \%$ \\
\hline Asthmatic & 1 & $4.2 \%$ \\
\hline Hypertensive \& diabetic & 3 & $12.5 \%$ \\
\hline $\begin{array}{c}\text { Stone size } \\
(\mathrm{mm}):\end{array}$ & \multicolumn{2}{|c|}{$\begin{array}{c}28 \pm 3.70 \\
(22-35)\end{array}$} \\
\hline $\begin{array}{c}\text { Stone density } \\
(H U):\end{array}$ & \multicolumn{2}{|c|}{$\begin{array}{c}986.1 \pm 273.9 \\
(385-1570) \\
\end{array}$} \\
\hline Variable & $\mathrm{NO}(24)$ & $\%$ \\
\hline $\begin{array}{l}\text { Stone location: } \\
\text { Right renal pelvis } \\
\text { Left renal pelvis } \\
\end{array}$ & $\begin{array}{l}10 \\
14 \\
\end{array}$ & $\begin{array}{l}41.7 \% \\
58.3 \% \\
\end{array}$ \\
\hline $\begin{array}{l}\text { Radio-opacity: } \\
\text { Radio-opaque } \\
\text { Radio-lucent }\end{array}$ & $\begin{array}{c}21 \\
3\end{array}$ & $\begin{array}{l}87.5 \% \\
12.5 \%\end{array}$ \\
\hline
\end{tabular}


Table 2. Clinical data in the study group.

\begin{tabular}{|c|c|c|}
\hline \multirow[b]{2}{*}{ Variable } & \multicolumn{2}{|c|}{ The study group(24) } \\
\hline & \multicolumn{2}{|c|}{$\begin{array}{c}\text { Mean } \pm \text { SD } \\
\text { (Range) }\end{array}$} \\
\hline $\begin{array}{l}\text { Pre-operative } H b \\
\text { (gm/dl): }\end{array}$ & \multicolumn{2}{|c|}{$\begin{array}{l}13.19 \pm 0.89 \\
(11.6-14.8)\end{array}$} \\
\hline $\begin{array}{c}\text { Post-operative } \mathrm{Hb} \\
\text { (gm/dl): }\end{array}$ & \multicolumn{2}{|c|}{$\begin{array}{l}12.71 \pm 0.85 \\
(11.2-14.2)\end{array}$} \\
\hline $\begin{array}{l}\text { Average } H b \text { drop } \\
\text { (gm/dl): }\end{array}$ & \multicolumn{2}{|c|}{$\begin{array}{c}0.47 \pm 0.26 \\
(0.1-1.4)\end{array}$} \\
\hline Variable & $\mathrm{NO}(24)$ & $\%$ \\
\hline $\begin{array}{l}\text { Hydro-nephrosis: } \\
\text { Grade } 0 \\
\text { Grade } 1 \\
\text { Grade } 2 \\
\text { Grade } 3\end{array}$ & $\begin{array}{l}5 \\
7 \\
7 \\
5\end{array}$ & $\begin{array}{l}20.8 \% \\
29.2 \% \\
29.2 \% \\
20.8 \%\end{array}$ \\
\hline
\end{tabular}

Table 3. Stone free rate, intra-operative complications and hospital stay in the study group.

\begin{tabular}{|c|c|c|}
\hline Stone free rate & NO(24) & $\%$ \\
\hline -Stone free & 21 & $87.5 \%$ \\
\hline $\begin{array}{c}\text {-Significant stone residual } \\
(4-10 \mathrm{~mm})\end{array}$ & 3 & $12.5 \%$ \\
\hline Intra-operative complications & $\mathrm{NO}(24)$ & $\%$ \\
\hline No & 24 & $100.0 \%$ \\
\hline Yes & 0.0 & $0.00 \%$ \\
\hline Variable & \multicolumn{2}{|c|}{$\begin{array}{l}\text { The study group(24) } \\
\text { Mean } \pm \text { SD } \\
\text { (Range) }\end{array}$} \\
\hline Duration of hospital stay (days) & \multicolumn{2}{|c|}{$\begin{array}{l}2.29 \pm 0.24 \\
(2-4)\end{array}$} \\
\hline
\end{tabular}

Table 4. Postoperative complications in the study group.

\begin{tabular}{|c|c|c|}
\hline Postoperative complications & NO(24) & $\%$ \\
\hline $\begin{array}{c}\text { (Total): } \\
\text {-Without complications } \\
\text {-With complications }\end{array}$ & $\begin{array}{l}13 \\
11\end{array}$ & $\begin{array}{l}54.2 \% \\
45.8 \%\end{array}$ \\
\hline Types of complications & No (11) & $\%$ \\
\hline $\begin{array}{c}\text { (Grade 1): } \\
\text { - Transient hematuria } \\
\text { - Fever } \\
\text { (Grade 2): } \\
\text { - U.T.I+fever } \\
\text { - Hematuria }\end{array}$ & $\begin{array}{l}4 \\
2 \\
3 \\
2\end{array}$ & $\begin{array}{c}16.7 \% \\
8.3 \% \\
\\
12.5 \% \\
8.3 \%\end{array}$ \\
\hline
\end{tabular}


Table 5. Operative outcome in the study group.

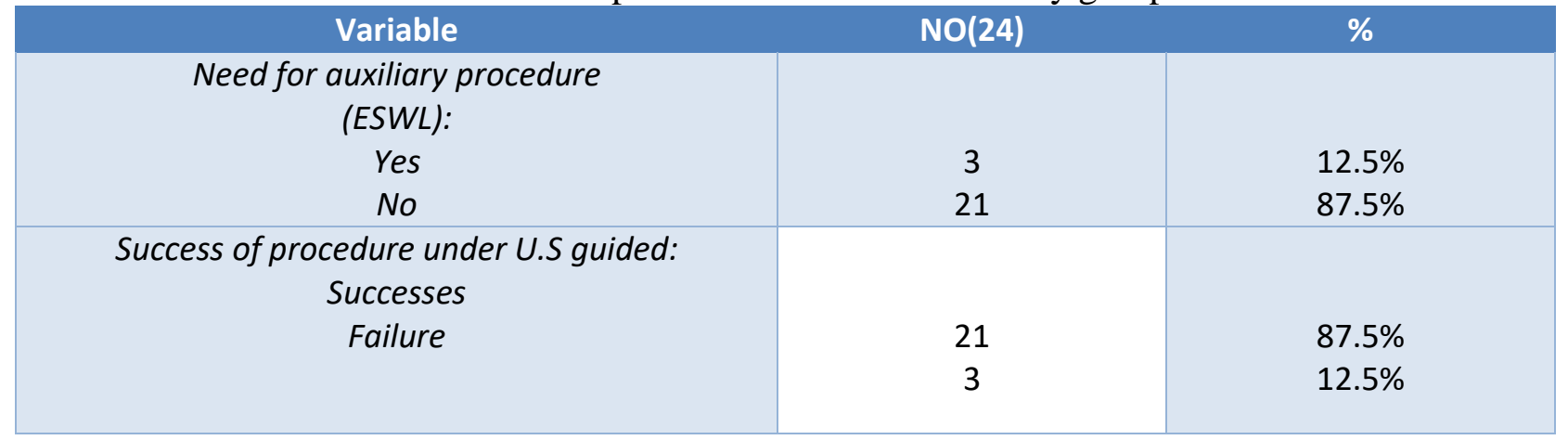

\section{DISCUSSION}

Currently the most common method to treat large renal stones that cannot be treated by SWL, is PCNL [7].

To perform the PCNL, proper pelvicaliceal system puncture is a crucial step. using fluoroscopy during this method is accompanied by exposing the medical staff as well as the patients to radiation. such radiations may lead to hazardous effects on various organs including the gonads, eyes, bone marrow, and thyroid [8], Sterility has also been reported by exposure to high doses of radiation (5-6 Gy) [9].

So X-Ray-free ultrasound-guided percutaneous nephrolithotomy may be performed for treatment of single renal pelvis stone

our study group, 24 patients (19 males and 5 females) with a mean age of $(35.8 \pm 8.4)$ (range from 23 to 51) years were enrolled in our study, Their BMI mean were $(23.5 \pm 3.8)$ (range from 18 to 30$) \mathrm{kg} / \mathrm{m} 2,(70.8 \%)$ of the study group did not have any chronic diseases, $(12.5 \%)$ of them were hypertensive, $(12.5 \%)$ were hypertensive \&diabetic, and (4.2\%) were asthmatic.

Stone characteristics were, stone size was (mean $\pm \mathrm{SD}=28 \pm 3.70) \mathrm{mm}$, stone density was (mean $\pm \mathrm{SD}=986.1 \pm 273.9) \quad \mathrm{HU}$, stone location was the right renal pelvis in 10 patients $(41.7 \%)$ and the left renal pelvis in 14 patients $(58.3 \%)$, also according radio-opacity $(87.5 \%)$ of stones were radio-opaque while $(12.5 \%)$ were radio-lucent, also regarding hydronephrosis, it was categorized as either absent or present based on the radiology report and confirmed at the time of surgery, $(20.8 \%)$ of our study group had grade 0 hydronephrosis, (29.2\%) had grade 1 \& 2 hydronephrosis and (20.8\%) had grade 3 hydronephrosis.

Our results show of 24 patients, 21 cases $(87.5 \%)$ were performed with complete US guidance ( successful cases ), of the remaining 3 cases $(12.5 \%)$ we failed to get an access under US guidance so we needed to conversion to conventional fluoroscopic guidance ( failed cases ) after 3 trials under US guidance .

Similar to our results Hosseini et al. reported in their study on 47 patients, underwent US guided PCNL, with a mean stone size of $31.5 \mathrm{~mm}$ (range $24-46 \mathrm{~mm}$ ). All stones were located in the renal pelvis with mild to moderate hydronephrosis, there was failure occurred in two patients $(4.25 \%)$, and fluoroscopy was needed [10]

Also Hosseini et al. reported in their study on 357 patients, underwent pure ultrasound-guided PCNL, with a mean stone size of (33.5) mm, stone locations were lower calyx in 68 patients and renal pelvis in 174 patients or both in 115 patients, with mild to moderate hydronephrosis, there was access failure occurred in ten obese patients $(2.8 \%)$ and fluoroscopic guidance was required [10].

On the contrary Basiri et al. reported in their study which included 19 adult patients, underwent US guided PCNL, they reported that the PCS could be successfully approached in all patients under US guidance and no X-ray was used in any setting of the procedure in their study (12].

Also on the contrary chi et al. reported in their study which included 38 PCNL procedures performed with renal access and tract dilation purely under ultrasoundguidance, reported that intraoperatively fluoroscopic screening was used only for 
nephrostomy tube placement, positional confirmation and readjustment [13]. However they were only assessing Ultrasound Guidance for renal tract access and dilation reduces radiation exposure during PCNL.

Regarding total operative time (defined as time calculated from initial cystoscopy for ureteral catheter placement until the placement of JJ stent), our results shows a total operative time (range60-100) minutes.

On the contrary Basiri et al. reported a total operative time was (mean 111) (range 70-180) minutes[12], which is more than our results but most likely because they had patients with renal stones more than $5 \mathrm{~cm}$ and included patient with renal anomaly (horse shoe kidney).

Also in a study conducted by Gamal et al. in which the procedure was applied to 34 patients, with unilateral single stone pelvis in a moderately to markedly dilated pelvicaliceal system, they reported that thier mean operative time was 60 minutes (range 40-85 min) [8], which is less than our results most likely because we routinely inserting a dj stent at the end of operation .

In our study the postoperative hospital stay of our study group (24 patients) was (mean $\pm \mathrm{SD}=2.29 \pm 0.24$ ) (range 2-4) days.

Similarly Gamal et al. reported that their mean postoperative hospital stay was (mean 1.4) (range 1-3) days (8].

On the contrary Hosseini et al. reported that their mean postoperative hospital stay was (mean 4.1) (range3-5) [10].

Also Basiri et al. reported that their mean postoperative stay was $(3.6 \pm 1.4)$ days [12].

Regarding stone free rate in our study group, The over all SFR in our study group (24 patients) was $(87.5 \%)$ and $(12.5 \%)$ had significant stone residual $(4-10 \mathrm{~mm})$.

Similarly Basiri et al. reported that their stone free rate was $(84 \%)$ in their study [12].

Also Gamal et al. reported that (94\%) of their patients were stone free on postoperative day [8].

Regarding need for auxiliary procedure, In our study group (24 patients), we had 3 patients with significant stone November. 2020 Volume 26 Issue 6 residual measuring $(5,7,8) \mathrm{mm}$, shifted to auxiliary maneuver (ESWL ) and became stone free after one session of ESWL was performed after $2 \mathrm{wks}$ and the stone free rate became $100 \%$, and in our study no needed for 2nd look PCNL.

Similarly Gamal et al. in their study had two patients with residual stones that measured 8 and $10 \mathrm{~mm}$, SWL was applied on the second day, and the patients became stone free 10 days postoperatively and no needed for 2nd look PCNL [8].

On the contrary Hosseini et al. reported in their study, there were residual fragments with sizes of $10-12 \mathrm{~mm}$ in seven patients, all of them underwent shock wave lithotripsy, in one patient, a fragment measuring 7-8 $\mathrm{mm}$ migrated into the distal part of the ureter, it was fragmented with ureteroscopy two days after the procedure, in two patients who had large more than $15 \mathrm{~mm}$ residual stone redo pcnl was performed two days after the first procedure [11].

In our study group (24 patients), regarding intra operative complications, our results show no one of the study group had any intraoperative complications (100.0\%).

In contrast with Basiri et al. reported one patient $(5 \%)$ who had significant hemorrhage during the procedure [12].

Also in our study group (24 patients), no blood transfusion or open surgery was required, access related complications, like organ injury ( colon injury), and perinephric collection, were not reported in any patient.

Similar to our results chi et al. reported no blood transfusions were necessary in either group and there was not any access related complication in any patient [13].

On contrary Basiri et al. reported in their study one patient required blood transfusion (5\%), also visceral organ injury was not reported in any patients [12].

In our study group, there were no injuries of surrounding organs (like colon), or pneumothorax, which almost attributed to the appropriate positioning of the puncture into the desired calyx under US guidance, and that the procedures were performed by an experienced urologist.

Regarding

postoperative complications were mostly characterized as 
Clavien-Dindo class 1 or 2 , the over all postoperative complications rate in our study group (24 patients) were $(54.2 \%)$ without any complications and (45.8\%) with minor complications in form of : $\{4$ patients had transient hematuria (grade I Clavien System) managed using good hydration, 2 patients had only fever (grade I Clavien System) managed with antipyretic $\} \&\{3$ patients had UTI and fever (grade II Clavien System) managed using antipyretic and antibiotics according to urine culture\& sensitivity, also 2 patients had hematuria (grade II Clavien System) managed using good hydration, anti-hemorrhage drugs\}.

Similar to our results Hosseini et al. reported in their study low grade Fever was seen in nine patients resolved with no intervention except antipyretic and routine antibiotic administration, Headache, which developed 4 to 5 days after the operation in seven patients was managed conservatively with analgesics. Colic developed in eight patients; three patients had urinary tract infections, one patient had obstruction because of a migrated stone fragment in the ureter, and in three patients, there was suspicion of PCS perforation, No sepsis or severe bleeding occurred. There were no major intraoperative or postoperative complications [10].

\section{CONCLUSION}

Percutaneous nephrolithotomy with ultrasound guidance is a good alternative to the fluoroscopic method, in patients with single renal pelvis stone with mild to moderate hydronephrosis, It has some advantages such as : can be performed safely without radiation exposure to the patients and medical staff, with satisfactory outcomes without any major complications, prevention of adjacent organ damage and efficient method for localizing both radio-opaque and radiolucent renal stones intraoperatively.

We recommend using ultrasound guidance during PCNL, for its efficacy and safety especially in patients with single renal pelvis stones, and to perform multi-center studies with large sample size and patients with multiple stones and larger stone size.

Conflict of Interest : Nothing to declare Financial Disclosures : Nothing to declare November. 2020 Volume 26 Issue 6

\section{REFERENCES}

1. Rodrigues PL, Rodrigues NF, Fonseca J, Lima E, Vilaça JL. Kidney targeting and puncturing during percutaneous nephrolithotomy: recent advances and future perspectives. Journal of endourology 2013; 27(7), 826-834.

2. Patel SR, Nakada SY. The modern history and evolution of percutaneous nephrolithotomy. Journal of endourology 2015; 29(2): 153-157.

3. Majidpour H S. Risk of radiation exposure during PCNL. Urology journal 2010; 7(2): 87-89.

4. Chu C, Masic S, Usawachintachit $\mathrm{M}, \mathrm{Hu}$ W, Yang W, Stoller M, et al. Ultrasoundguided renal access for percutaneous nephrolithotomy: a description of three novel ultrasound-guided needle techniques. Journal of endourology 2016; 30(2), 153-158.

5. Li J, Xiao B, Hu W, Yang B, Chen L, Hu $\mathrm{H}$. Complication and safety of ultrasound guided percutaneous nephrolithotomy in 8 025 cases in China. Chinese medical journal 2014; 127(24), 4184-4189.

6. Lantz AG, O'Malley P, Ordon M, Lee JY. Assessing radiation exposure during endoscopic-guided percutaneous nephrolithotomy. Canadian Urological Association.Journal 2014; 8(9-10),347.

7. Karami H, Rezaei A, Mohammadhosseini M, Javanmard B, Mazloomfard M, Lotfi, B. Ultrasonography-guided percutaneous nephrolithotomy in the flank position versus fluoroscopy-guided percutaneous nephrolithotomy in the prone position: a comparative study. Journal of endourology 2010; 24(8), 1357-1361.

8. Gamal W M, Hussein M, Aldahshoury M, Hammady A, Osman M, Moursy E, et al . Solo ultrasonography-guided percutanous nephrolithotomy for single stone pelvis. Journal of endourology 2011; 25(4), 593-596.

9. Hall EJ, Giaccia AJ. Hereditary effects of radiation. In: McAllister L, Bierig L, Barrett K (eds) Radiology for Radiologist 2006, Chap 11, 6th edn, Sect 1. Lippincott Williams \& Wilkins, Philadelphia, pp 1156-1157

10. Hosseini MM, Hassanpour A, Farzan R, 
Yousefi A, Afrasiabi MA. Ultrasonography-guided percutaneous nephrolithotomy. Journal of endourology 2009; 23(4), 603-607.

11. Hosseini MM, Yousefi A, Rastegari M. Pure ultrasonography-guided radiation-free percutaneous nephrolithotomy: report of 357 cases. Springerplus 2015; 4(1): 313.

12. Basiri A, Sichani MM, Hosseini SR, Vadjargah AM, Shakhssalim N, Kashi AH, et al. X-ray-free percutaneous nephrolithotomy in supine position with ultrasound guidance. World journal of urology 2010; 28(2), 239-244.

13. Chi T, Masic S, Li J, Usawachintachit M. Ultrasound guidance for renal tract access and dilation reduces radiation exposure during percutaneous nephrolithotomy. Advances urology, 2016.

\section{Cite This Article - VANCOUVER Style}

ashour, A., khalil, S., omran, M., Eliwa, A. X-Ray-Free Ultrasound-Guided Percutaneous Nephrolithotomy at Zagazig university hospital. Zagazig University Medical Journal, 2020; (10891100): -. doi: 10.21608/zumj.2019.15688.1405 